\title{
Road lighting and pedestrian reassurance after dark: A review
}

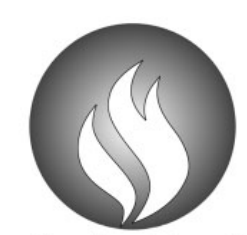

The Society of Light and Lighting

\author{
S Fotios $\mathrm{PhD}^{\mathrm{a}}, \mathbf{J}$ Unwin $\mathrm{MSc}^{\mathrm{a}}$ and $\mathbf{S}$ Farrall DPhil ${ }^{\mathrm{b}}$ \\ ${ }^{a}$ School of Architecture, The University of Sheffield, Sheffield, UK \\ ${ }^{\mathrm{b}}$ School of Law, The University of Sheffield, Sheffield, UK
}

Received 20 November 2013; Revised 22 January 2014; Accepted 28 January 2014

\begin{abstract}
This paper concerns road lighting for pedestrians and how this aids reassurance, their confidence when walking alone after dark. Evidence from past studies that lighting enhances reassurance is supported by the findings of an unfocussed approach that aimed deliberately to avoid focus on lighting or fear, thus to counter the unintended potential for focussed, quantitative methods to lead towards such a finding. Review of the characteristics of lighting suggests an optimum illuminance of 10 lux, of high S/P ratio, and aimed toward the pedestrian and natural elements of the environment, will enhance reassurance. Further research is needed to validate the optimum illuminance, the appropriate metric for characterising lamp spectral power distribution, and the most desirable aims of spatial distribution.
\end{abstract}

\section{Introduction}

This paper concerns road lighting in residential areas, these being areas of a village, town or city which are suitable for, or are occupied by, dwellings. In such areas, it is normal to provide lighting that focuses more, but not exclusively, on the needs of pedestrians compared to those of drivers. ${ }^{1}$ Road lighting should contribute to provision of a road (or other pedestrian foot path) which is safe for pedestrians to use and which also is perceived to be safe.

In this study, reassurance is used to describe the confidence a pedestrian might gain from road lighting (amongst other factors) to walk along a road, in particular if walking alone after dark. Reassurance is used here to encompass the terms perceived safety and fear of crime used in past studies; a road in which reassurance from lighting provides

Address for correspondence: Steve Fotios, School of Architecture, University of Sheffield, The Arts Tower, Western Bank, Sheffield S10 2TN, UK.

E-mail: steve.fotios@sheffield.ac.uk confidence to walk is one that offers higher perceived safety and lower fear of crime. There are doubts over what terms such as fear of crime mean as a social phenomenon ${ }^{2}$; past studies do not clearly discriminate between perceived safety and fear of crime, and in the review by Lorenc et al., ${ }^{3}$ evidence from both were collated on the same dimension. Reassurance is that which provides the comfort that makes someone feel less worried, ${ }^{4}$ less afraid or doubtful ${ }^{5}$ and restores confidence. ${ }^{6}$ UK government planning guidance ${ }^{7}$ commented on the need for local development plans to 'reassure the public by making crime more difficult to commit. . . and provide people with a safer more secure environment' by using the '...deterrent effects of good design, layout and lighting'. ${ }^{8}$ Wayfinding studies use the term reassurance when discussing the use of signage and landmarks to confirm that the correct route is being followed..$^{9,10}$

A place will be considered unsafe (i.e. having a risk of criminal offences, violence or threats) if it offers refuge to offenders and 
limited prospect and escape to potential victims. ${ }^{1}$ These are physical features of an environment. It is important to perceive a potential danger as soon as possible ${ }^{12}$ : prospect is a measure of how well a person can look ahead to anticipate whom or what he/ she is likely to encounter. Good prospect also implies that the pedestrian is visible to others. Escape is the opportunity for exit at various points along the path or in a location. Narrow alleys are considered more dangerous than wide alleys ${ }^{13}$ as they are less likely to suggest good possibilities for escape. Natural and artificial features along a route could provide a place to hide and these have dual possibilities, providing either a place for a potential attacker to wait out of sight (concealment) or a place for a potential victim to hide (refuge). People feel the safest if they have a good overview of the space in which they are moving and if they have the feeling that they are supported by other users, ${ }^{14}$ and this may be captured by the expressions visibility of others and visibility by others ${ }^{15}$ or alternatively, how much can I see? and how much am I seen ? $^{14}$

Reassurance decreases (or fear increases) after dark because there are fewer people around, contributing to feelings of isolation from help if needed, and because visibility is reduced, which may provide offenders with more opportunities for concealment and may make it more difficult to identify escape routes should they be necessary. ${ }^{16}$ Functionally, the most obvious and only certain effect better lighting can have is to change how well people can see: Increasing the adaptation luminance increases the speed of visual processing, improves the discrimination of detail, makes colour judgements more accurate and increases the distance at which we can see anything suspicious. ${ }^{17}$ Road lighting enhances vision after dark, thus we expect road lighting to improve the visibility of others and visibility by others, and thus to improve feelings of reassurance.
This paper has two aims. First, to identify evidence that road lighting enhances reassurance. While the literature review identified some evidence, changes in reassurance may, in some cases, have been a response to obvious changes in lighting or influenced by questionnaire design. Measurement of reassurance, as with any perceptual attribute, is prone to bias; questionnaire design and the mode of evaluation can affect the outcome. ${ }^{18-20}$ Hence, an experiment is reported that attempts to evaluate the contribution of lighting to reassurance without a specific focus on lighting. Following the conclusion that lighting matters, the second aim is to determine how this enhancement is effected by three key variables of lighting that the designer is able to manipulate - illuminance, spatial distribution and spectral power distribution (SPD) - a step toward establishing criteria for design guidance.

\section{Lighting and reassurance}

\subsection{Experimental studies}

The first aim was to establish whether lighting enhances reassurance, here considering studies which treat lighting as a single entity (for example present vs. absent or improved vs. existing) rather than the precise characteristics of lighting.

If light has an effect on reassurance, then a large difference in lighting conditions should lead to a large effect. This can be seen in the results from Loewen et al. ${ }^{21}$ who compared photographs of scenes in daylight (with light) and at night (without light). Loewen et al. presented 16 photographs, these being two different outdoor scenes for each of the eight combinations of light, open space and refuge, the items most frequently identified in their pilot study for which participants were asked to provide ratings of items including safety. The results are shown in Figure 1. In all four situations regarding the presence or absence of open space and refuge, with light was rated 


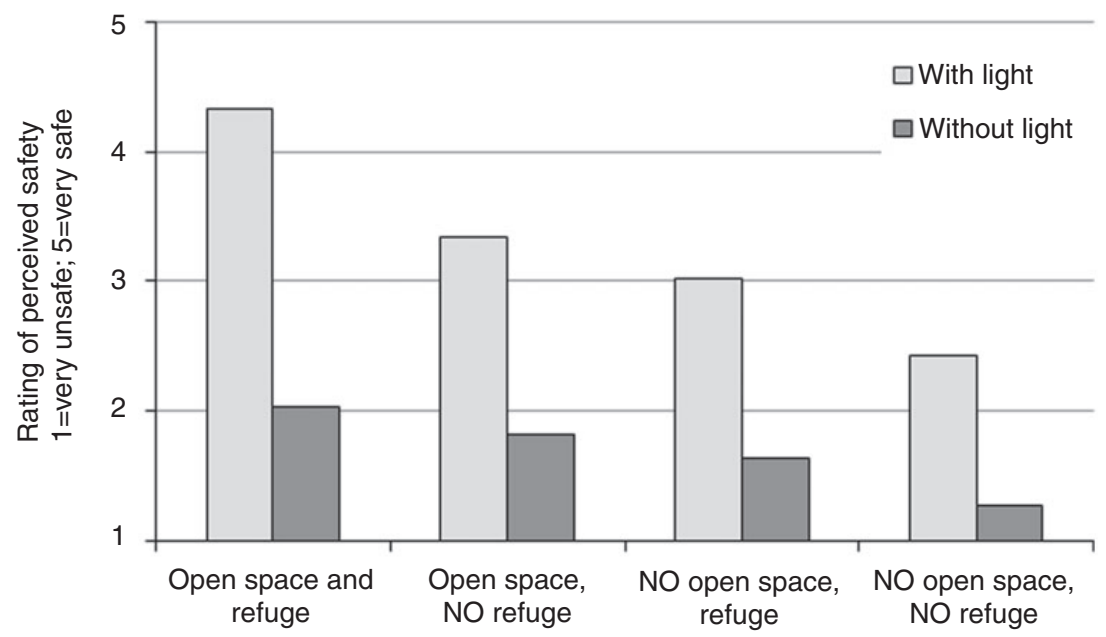

Figure 1 Mean ratings of perceived safety of images of outdoor scenes as reported by Loewen et al. ${ }^{21}$ Note that with light means scenes in daylight and without light means scenes at nighttime.

safer than without light, and this effect was larger than that found for differences in open space or refuge.

Hanyu $^{22}$ also sought ratings of items including safety whilst observing photographs of real locations, these being 20 nighttime locations from a university campus, and found a relationship between ratings of safe and lighting that was considered to be bright and uniform. Photographs (and other methods of simulation) may yield different responses to those gained in real spaces because they tend not to provide audio cues and because people tend to focus more on details in virtual environments than in reality. ${ }^{23}$ Photographs fail to capture the dynamics of a real environment and its context. ${ }^{23,24}$ Bishop and Rohrmann ${ }^{25}$ compared evaluations of an outdoor environment in a real outdoor space and a video simulation (which included pre-recorded environmental sounds) of the same environment, under both nighttime and daytime conditions. The simulated environment did not yield the same results as the real environment: Evaluations made from the simulation tended to overrate the negative effects (e.g. disliking and threat) and underrate the positive effects (pleasure, naturalness and overall liking). Information recall was found to be more accurate in the real environment.

Many studies of lighting and reassurance have been conducted in outdoor locations. While the context is clearly more appropriate than evaluation of photographs, it is more difficult to set up well-defined conditions and robust evaluations. Lorenc et al. ${ }^{3}$ included 16 studies of the installation or improvement of lighting within their review of environmental interventions and they considered the quality of evidence to be generally low. While uncontrolled studies showed reductions in fear, they tended not to report significance and the effect was not replicated in studies considered to be more rigorous.

Painter $^{26,27}$ surveyed pedestrians in three locations in London (Edmonton, Tower Hamlets, and Hammersmith and Fulham). In these three roads, the existing low-pressure sodium (LPS) lamps were replaced with highpressure sodium (HPS) lamps, these being installed to achieve an average of 10 lux 
(minimum 5 lux) while the original lighting provided less than 3.5 lux. Pedestrians were questioned about their experience within 5 minutes' walk of the location over the past 12 months. It was reported that 'over $90 \%$ of pedestrians interviewed in all locations thought that fear of crime in the surrounding area had decreased' following installation of the HPS lighting although there is no statistical analysis. This suggests a change of lighting has an effect, although it is not possible to determine whether it was the broader spectrum or higher illuminance of the HPS lighting that led to the apparent improvement in reassurance.

Nair et $a l .^{28}$ carried out before and after surveys following improvements to street lighting in a residential area in Glasgow, resulting in a $6 \%$ reduction in the number of people worried about assault and harassment. However, the reported changes in opinions are not statistically analysed and the changes are small (e.g. 6\% means two of the 33 respondents changed opinion). The results reported for one question serve to demonstrate the questionable validity of the Nair et al. data; in the survey carried out before the lighting improvements had taken place, $17 \%$ of respondents reported recent improvement in lighting despite there being no such action (and, in the after survey, this was only 18\%).

Two studies were conducted in outdoor locations in Japan. Okuda et al. ${ }^{29}$ carried out an on-road survey after dark in which respondents were asked to indicate roads where they felt most secure and least secure and to identify the factors that led to these responses. They found that dark road lighting and an empty road were the most frequently mentioned by respondents (both 36\%), followed by narrow roads $(25 \%)$ and no road lighting $(20 \%)$. Koga et al. ${ }^{30}$ sought on-road ratings of the visual environment, concluding that feelings of security increased in light and busy streets: factor analysis derived five common factors from the evaluated items (liveliness, order, openness, intimateness and unity) and lighting was essential to every factor.

A third approach to investigating reassurance is to question residents whilst they are at home, an evaluation by memory of settings known only to the respondent. van Cauwenberg et $a l .{ }^{31}$ reported a survey of 48,879 people aged more than 65 years old which included a question asking if street lighting was sufficiently present in the neighbourhood (Yes/No response) and a series of rating scales to measure feelings of safety: The results suggest the presence of street lighting increases the feeling of safety. Bernhoft and Carstensen $^{32}$ surveyed 1905 people (1017 older people aged more than 70 years old; 888 people aged 40-49 years old) in two Danish cities. One question asked 'Which of the following conditions are most important for your route choice when walking/cycling in your hometown?' and respondents were asked to choose a maximum of three from eight given statements including 'Good street lighting'. The results are shown in Figure 2, these being the percentage of people identifying each of the eight statements. Bernhoft and Carstensen $^{32}$ report the results for males and females separately; Figure 2 presents an estimated average of these (in only two cases were the differences between male and female responses suggested to be significant). Good street lighting was not the most frequent reason for route choice. For the younger age group, getting to the destination quickly and by the most direct route were more important; for the older group, all items were more frequently important than good street lighting. Note, however, that while it was possible to not pick good street lighting as a criterion for route choice, many did: As concluded by others, ${ }^{33}$ there are some people, even if only a minority, for whom better lighting makes a real difference. If the road lighting in Denmark is already considered to be good by the public, they may have been less likely to consider this as a reason for route choice. 


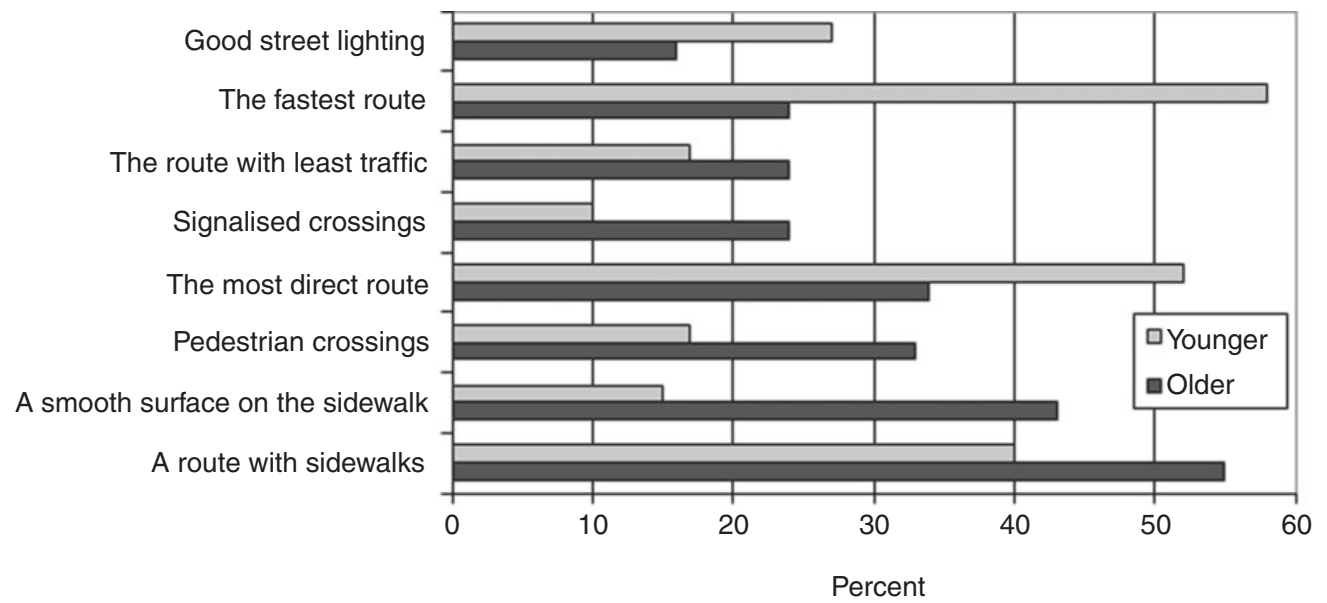

Figure 2 Conditions of importance for pedestrians' route choice, from Bernhoft and Carstensen. ${ }^{32}$ Note: these values are estimated from their Figure 1 and are average values of the male and female responses presented.

\subsection{Leading the witness}

In their review, Lorenc et al. ${ }^{3}$ made a quality assessment through consideration of issues including selection bias, confounders and data collection, leading to conclusions as to whether the data were of high, medium or low quality, and their analysis placed greater emphasis on the higher quality studies. In the current paper, we consider that the choice of visual scenes and survey instrument may have unfairly prompted respondents to focus on lighting. Thus, while several stu$\operatorname{dies}^{21,22,26,27,29-32}$ tend to suggest that lighting enhances reassurance, the procedures used may have raised the prominence of lighting as a factor, thus unintentionally prompting participants to respond in a manner which indicates that lighting is important.

In the photographs presented by Loewen et al. $^{21}$ and Hanyu, ${ }^{22}$ differences in lighting may have been the most visually prominent change in the scenes, in particular for the daytime versus nighttime photographs used by Loewen et al., thus inflating the effect of lighting relative to other environmental features. Evaluations in field trials carried out shortly before and shortly after improvements to the lighting ${ }^{26,27}$ may be a response to an obvious change rather than to the qualities of the new lighting: Note here that Painter's ${ }^{26,27}$ 'improved' lighting used HPS lamps, while in a more recent field study ${ }^{34}$ HPS are the unsatisfactory lighting being replaced by metal halide (MH) lamps.

In Bernhoft and Carstensen ${ }^{32}$ and possibly also Okuda et al. ${ }^{29}$ the respondents chose from a small list of options including lighting, the provision of which may have raised their prominence compared with a free and unguided consideration. We do not know if these responses were their most important route decision criteria and similarly we do not know the relative importance of their choices. For example, it may be that a route with sidewalks is by far the more important consideration for older people and their other choices were relatively minor considerations, perhaps reported only to comply with the survey instructions. Similarly, the police assessing locations found by Vrij and Winkel $^{35}$ to be unsafe may have identified poor lighting simply because it was one of the criteria they were prompted to assess.

Rating scales were used in some studies $^{21,22,30,31}$ and these may force test participants to evaluate an item they may 
otherwise have not chosen to evaluate or considered to be relevant. This can be seen in Acuña-Rivera et al. ${ }^{18}$ who used evaluations of digitally manipulated photographs of a residential road to investigate the effect of signs of incivility. Their qualitative method asked test participants to provide at least five words that best expressed their impression of the scene: while test participants referred to physical disorder, only a few mentioned crime and safety. Their quantitative method used a series of rating scales and these results revealed an association between signs of incivility and safety in that the more disordered a place was rated, the more it was rated unsafe. These data reveal that evidence of signs of incivility and reassurance may be method dependent. The rating scale approach forced test participants to give an evaluation of reassurance that was not otherwise forthcoming in the quantitative procedure. Similarly, Ramsay and Newton ${ }^{33}$ refer to an unpublished study by Charlton of lighting in Deptford, at the time a high-crime inner-city area of London: When asked to list the three main disadvantages of their location only $8 \%$ mentioned poor lighting, but when asked specifically whether better lighting would decrease fear of crime, $80 \%$ agreed.

\subsection{A question of fear}

Farrall et al. ${ }^{36}$ discuss the fear of crime and suggest that fear recorded in surveys is as much a methodological artefact as an empirical reality. Poor question wording, the desire to cooperate with surveys, and media and political interests in the fear of crime have contributed to a scenario in which the fear is continually recreated both socially as a topic for debate and at the individual level: Surveys in this situation may not merely measure fear, and they may actually create and recreate it. The traditional methods consistently overemphasise the levels and extent of fear of crime. $^{2,37}$
One problem associated with the measurement of whether lighting effects reassurance is that there are many ways in which fear of crime is manifest and it is often unclear what is actually being measured. ${ }^{2}$ There are many reasons for this. Test participants are often asked whether they are very, fairly or not very worried (or afraid) of becoming a victim of crime, but they are not asked how often they worry, nor when they worry, ${ }^{38}$ nor what effects these worries have on their everyday lives. ${ }^{39}$ Using standard measures, some people report being worried without having worried recently. ${ }^{2,40}$ Researchers do not typically have access to people when they are actually afraid but instead have focussed on anticipated rather than actual fear. ${ }^{2}$ Test participants will make an expression of opinion even if they have no real opinion, for example because the survey appears to be for the common good and will thus give an opinion which they hope will be helpful. ${ }^{2}$ There may be bias due to the retrieveability of instances, ${ }^{41}$ the subjective probability (or perceived risk) of crime may rise when one experiences evidence of crime. The effect of methodology on reassurance measures can be seen from a review (of respondents' answers to first a survey and then qualitative questions about fearful episodes) where in only 15 of 64 interviews was there no discrepancy in their answers. ${ }^{36}$

Problems within the approach to measuring fear of crime can generate the impression of a large proportion of the population who fear crime $2,37,42$; according to Matsui ${ }^{43} 85 \%$ of females 'always' fear being a victim of street crime. Men are more likely than women to under-report their concerns about becoming a victim of crime because of socially desirable responding; when this is taken into account, men's fears can outstrip women's fears. ${ }^{2,44}$ Similarly, some responses may be exaggerated by perceptually contemporaneous offenses. ${ }^{45}$ For example, women may give higher levels of fear of burglary than men 
because when a woman is asked about burglary, she gives an answer about rape, since most people wrongly assume that they will be in a house when it is burgled, and that the burglar would attempt to harm them. Such responses are inadvertently not to do with how worried they are about the likelihood of assault happening but rather, if it did happen how much it would affect them.

Thus, it is possible that directly asking questions about fear and safety raises a problem that is otherwise non-existent. ${ }^{18}$

\subsection{Summary}

While there is evidence from past studies to suggest that the presence of lighting enhances pedestrian reassurance, it is possible that the procedures used led the respondent to indicate effects of lighting and fear; because lighting was one of a limited set of responses available, ${ }^{32}$ because it was an obvious difference between evaluated scenes, ${ }^{21}$ or because lighting and fear were the focus of the rating scales presented to respondents for which it is unlikely they were permitted to respond 'not relevant'. ${ }^{21,22,30}$ In two studies, ${ }^{29,30}$ insufficient data are reported to substantiate the findings (e.g. not stating the questions posed to respondents) in which case the findings may not be considered to be credible, or should at least be treated with caution. If we do not know the instruction to which participants responded (i.e. the question and response scale), then it is difficult to place the response into context or give consideration to potential response biases. It may be that enforced space limitations prevent inclusion of the questionnaire in written report: These two studies ${ }^{29,30}$ were published in conference proceedings which until recent changes to electronic proceedings tended to limit the length of articles.

It is difficult, if not impossible, to avoid bias completely in a quantitative evaluation. One approach to countering this limitation is to seek data from studies using different procedures, and if these converge toward the same conclusion, then some confidence may be placed in it. While the data above include variations in task (e.g. rating scales or pick from a list) and type of visual target (e.g. photographs, direct evaluation of outdoor scenes and memory evaluation of outdoor scenes), they use procedures that may have unintentionally raised lighting as a significant factor for reassurance

An alternative procedure was used by Vrij and Winkel ${ }^{35}$ who interviewed 854 residents in which they were asked to identify any locations in their home city (Enkhuizen, The Netherlands) that were considered to be unsafe. These locations were then reported to the police and assessed for features including poor lighting and crime rate. Of the 13 locations reported that were mentioned most frequently, the police assessment suggested lighting was poor in 11 areas, these also being the 11 not considered to have high crime rate. Absent from this study are the respondents' reasons as to why a location was considered not to be safe, and how the police made their evaluation as to whether the lighting was poor.

Therefore, an experiment was carried out to determine whether lighting would be revealed as a contributing factor to reassurance using a procedure that aimed to minimise aspects that might otherwise exaggerate the influence of lighting.

\section{Experiment}

\subsection{Method}

The aim of this experiment was to investigate whether road lighting is associated with pedestrians' feelings of reassurance when walking alone in residential areas after dark. The procedure was designed to avoid two problems found in previous work. First, there was no direct emphasis on lighting, either by direct questioning or by presenting target scenes with different lighting conditions. 


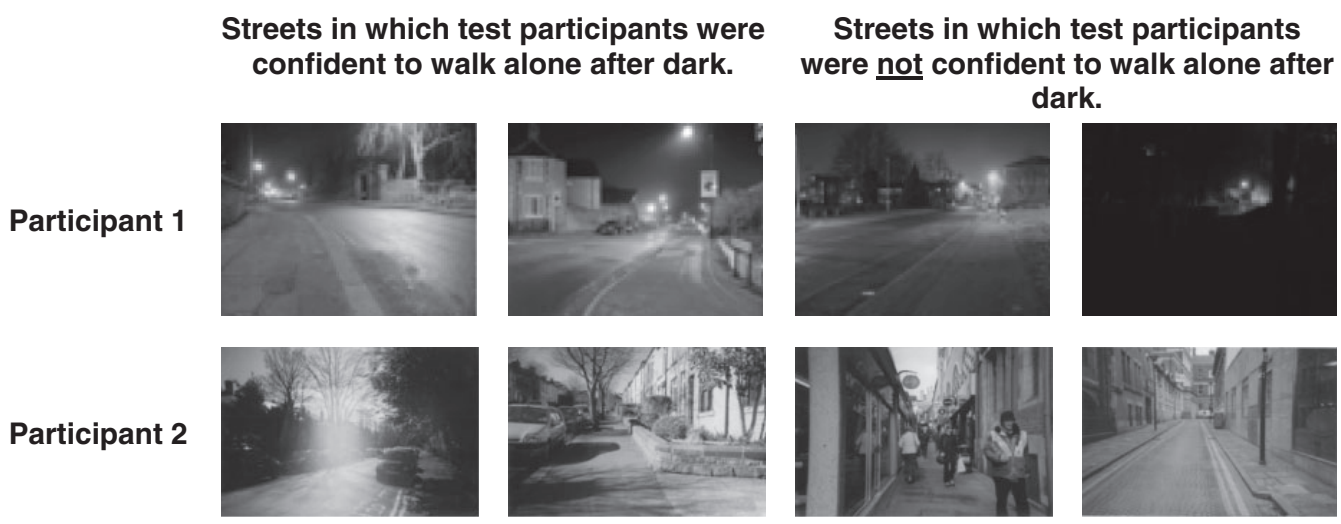

Figure 3 Sample of images received from two participants, showing areas considered to be safe (left) and not safe (right) in which to walk alone after dark.

Second, the experimenter avoided words such as 'safety' and 'fear' during communication with test participants in order to avoid priming test participants with the notion of fear.

Data were gathered during interviews with individual participants. Before being invited to interview, participants were asked to supply photographs of two roads where they felt confident to walk alone at nighttime and two roads where they did not feel confident to walk alone at nighttime. These photographs were subsequently used as discussion aids during the follow-up interview. Pilot studies are reported elsewhere. ${ }^{46}$ Participants provided their photographs purposefully for this experiment. They were given the option of using a disposable camera (with images subsequently developed by the experimenter), or of using their own digital camera. For some older participants, they identified the locations and the experimenter visited this place to capture photographs.

There were two stages of interview, carried out in the same order. In the first stage, participants were asked to describe characteristics of streets where they did and did not feel confident to walk alone and after dark, and this discussion did not involve visual cues or specific reference to place. In the second stage, the photographs provided by the test participant were used as visual prompts and they were asked to give reasons for their choices of locations. While this was a qualitative approach because it sought verbal descriptions of opinion rather than the numerically measureable behaviour associated with quantitative methods, ${ }^{47}$ subsequent analysis used quantitative measurement. We therefore refer to this experiment as unfocussed because the procedure did not purposefully draw attention to lighting, neither by the conditions examined nor by the questions asked. The procedure allowed place-specific discussion of cues to reassurance using real locations that were familiar to the test participants. Figure 3 shows a sample of the photographs received. The photographs received included some taken in daytime as well as after dark: Daytime photos were acceptable as the photos were used as a prompt for the location rather than evaluation being made of the photograph itself. Half of the participants were asked to comment first on the confident-to-walk areas and for the other half the not-confident-to-walk areas were discussed first.

Fifty-three participants were recruited. Twenty-six were students (aged 18-34 years 
with an approximate mean age of 24 years) and 27 were older people (aged 55-84 years with an approximate mean age of 68 years). These means are approximate because participants' ages were recorded in bins (i.e. 18-25, 26-34, 35-44, 45-54, 55-59, 60-64, 6574 and $75-84$ years) rather than their precise age and the mean was determined using the centre value of each bin. Both groups comprised approximately equal numbers of males and females. The elderly participants were recruited from local sheltered housing complexes, a University of the Third Age coffee morning and website, and notices placed in an art gallery in Sheffield. Student participants were recruited via an e-mail sent to all students at Sheffield University who had not unsubscribed from the volunteer mailing list. All test participants were paid a small fee to attend the interview.

If road lighting was mentioned frequently as a contributory factor, this would provide evidence that it matters. Transcripts of the 53 interviews were analysed by collating the reasons given by participants for the presence or absence of feelings of reassurance into categories, the meaning units of Burnard, ${ }^{48}$ and the frequencies of these reasons were used as the basis for interpreting importance. Seven categories were established: Access to help, familiarity, mobility, presence of CCTV, presence of threatening others, presence of road lighting and physical features. Three categories were chosen to represent the factors contributing to reassurance identified in past work: Access to help and light were noted by Loewen et al., ${ }^{21}$ and physical features included environmental features linked to concealment, prospect and escape as identified by Fisher and Nasar ${ }^{11}$ such as a narrow alley or an open view. The need for four additional categories was identified during analysis of the results: Familiarity, presence of CCTV, ease of mobility (e.g. nowhere to cross the road and an uneven pavement surface) and presence of threatening others. The respondents use of both positive and negative language was included, e.g. 'it was really dark with just one street light' indicated that poor road lighting contributed to low reassurance, while 'pretty well lit on both sides of the road' indicated that road lighting contributed to satisfactory reassurance. Note that if a test participant mentioned a reason category more than once per location in stage 2 , it was counted only once.

For analysis of validity, sample extracts of the transcribed interviews were re-analysed by others, ${ }^{48}$ three who were expert and six who were naïve with respect to their knowledge of lighting and reassurance. These people were asked to complete two tasks for separate sections of text: first, to identify issues associated with reassurance and second, to categorise issues according to the seven reassurance categories. For the first task, issues identified by the experimenter as related to access to help, lighting, familiarity and presence of threatening others were matched by at least eight of the nine validators. For the second task, the four categories identified by the experimenter (access to help, familiarity, lighting and physical features) were also noted by all nine validators except for three who did not identify familiarity as an issue. It was thus concluded that the experimenter's interpretation of the interview transcriptions to identify reasons for reassurance was fair.

Transcription of the interviews and subsequent coding demanded significant effort from the experimenter. An alternative approach was used by Acuña-Rivera et al. ${ }^{18}$ in which test participants were asked to give five words or phrases that best expressed their impression of the place evaluated. This leads to fewer data but would allow for easier analysis. It would be interesting to determine if the two approaches lead to similar conclusions. 


\subsection{Results}

Figure 4 shows the percentage frequencies by which these categories were used to explain feelings of reassurance without the aid of visual prompts (stage 1). Of the 53 participants, 39 mentioned adequate road lighting as a reason for feeling reassured and 37 mentioned darkness or a lack of adequate lighting as a reason for not feeling reassured. Overall, 49 participants (92\%) expressed the presence/ absence of lighting as a factor contributing to reassurance. This is similar to the results of Loewen et al. ${ }^{21}$ who found when using their open question that 42 of 55 participants mentioned lighting. The presence or absence of access to help was the only factor mentioned with similar frequency to road lighting $(92 \%)$. Physical features, the presence of threatening others and familiarity were mentioned less frequently (51-62\%) and mobility and presence of CCTV by very few.

Figure 4 also shows the frequency with which the seven categories were used to explain feelings of reassurance with reference to the photographs (stage 2). There were 210 locations, these being four per participant except for one person (elderly male) who insisted that he was not scared at any location (in Sheffield) and provide photographs only of two places he was confident to walk alone.

The pattern of responses is similar to that found during discussion without visual prompt in that access to help and road lighting are the most frequent reasons and mobility and CCTV are the least frequent reasons. For 130 locations (62\%), road lighting was mentioned as a reason for the presence or absence of reassurance. This is a similar frequency to physical features $(55 \%)$, less frequent than access to help (78\%), but more frequent than familiarity $(30 \%)$ or the presence of threatening other people $(23 \%)$. Overall, $46(87 \%)$ of the 53 test participants mentioned street lighting as a reason for feeling reassured on at least one street of their choice and $45(85 \%)$ mentioned lack of adequate street lighting or darkness as a reason for not feeling reassured on at least one street of their choice.

In discussion of the features of environments where participants did and did not feel confident to walk alone and after dark, lighting was revealed to be a factor in many cases, and in this study, it was not prompted

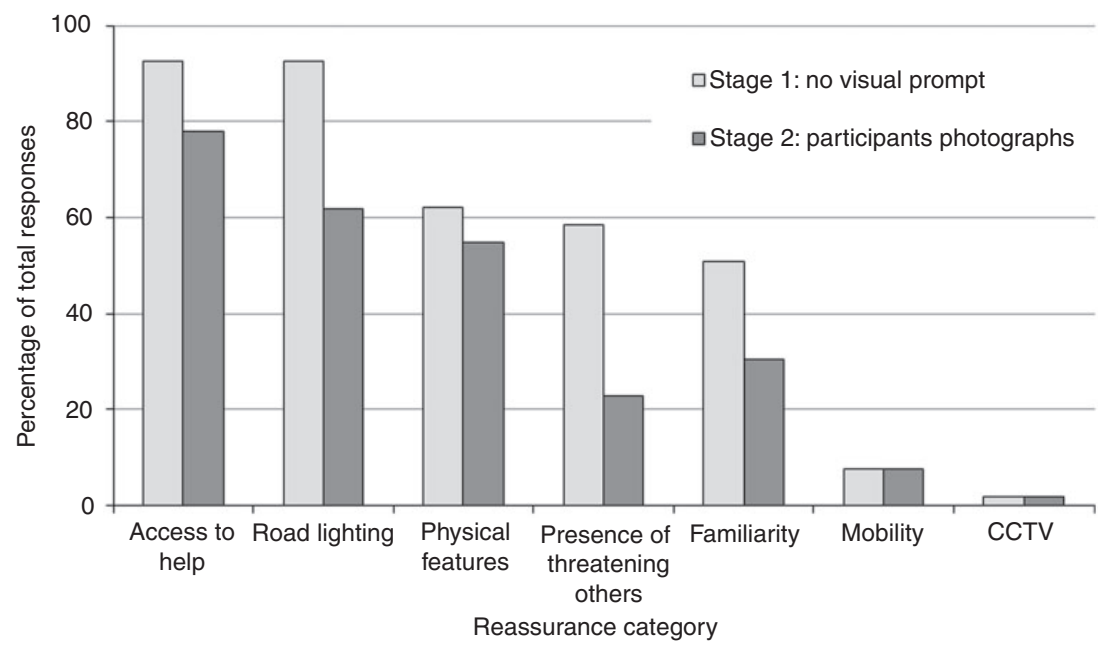

Figure 4 Percentage of total response with which reasons were given for feelings of reassurance when walking alone after dark during interview with and without visual prompts for specific locations. 
by choice of target image or raised in the survey instrument. This provides support for the findings of studies using quantitative approaches that lighting matters. Having drawn this conclusion, further evidence was sought as to how variations in the characteristics of lighting affect reassurance.

\section{Characteristics of road lighting}

\subsection{Illuminance}

The subjective impression of 'more light' is associated with safety. Blöbaum and Hunecke $^{12}$ surveyed eight locations around a university campus (seven outdoor places and one underground car park) and these were evaluated after dark through ratings concerning reassurance (e.g. I would walk along this place unaccompanied). The brighter locations were associated with higher levels of reassurance.

Horizontal illuminance is the main parameter of design guidance for residential roads $^{1,49}$ and higher illuminances tend to appear brighter. Five field studies have examined the influence on reassurance of an increase in illuminance of which three $e^{35,43,50}$ suggest this increases reassurance, one reported an increase in reassurance for females ${ }^{51}$ and one study was not considered to be credible. ${ }^{52}$ The three studies suggesting an effect used different approaches to implementing the change in illuminance. In the study by Matsui, ${ }^{43}$ lighting that was normally dimmed to $30 \%$ output would increase automatically to $100 \%$ when a person approached the area. In the study by Ishii et al. ${ }^{50}$ residents were asked to switch their porch lights on or off - when switched on, this increased horizontal illuminance (at the position of test participants) from 0.7 lux to 1.4 lux and increased vertical illuminance from 0.1 lux to 1.1 lux. Vrij and Winkel ${ }^{35}$ sought ratings of safety before and after illuminance was increased by a factor of 5 in the test location (the increases were 0.1 lux to 0.5 lux on the bridge, 0.18 lux to 1.11 lux on the cycleway and 0.24 lux to 1.31 lux on the footpath).

Atkins et al. ${ }^{51}$ provided a fourfold increase in illuminance (values not reported), and it is likely there was a simultaneous change in lamp type but this is not clear. Surveys of local residents were administered before and after the relighting did not reveal a general increase in feelings of safety but did suggest a significant increase in safety amongst females. Nair et $a l .^{52}$ also investigated reassurance before and after changes to the lighting in a street and concluded that higher illuminance led to a significant reduction in apprehensiveness. However, these data are not considered to be credible: The article fails to clearly report the questions and response scales; there is no a priori for their collation of responses as fearless, normal or timorous people; and there are no data to support their manipulation of the results to weight the results of the after survey to match the gender profile of the before survey.

A critical question for design is whether more illuminance will always be better or whether there is an optimum illuminance above which the increase in reassurance is negligible. The studies above provide insufficient evidence as to the possibility of an optimum illuminance, in part because each study examined only two levels of illuminance. Fortunately, there is one study that does provide evidence of an optimum illuminance, and this arises from the appraisal of several locations of different illuminance and from a novel approach to interpretation of the data. Boyce et al. ${ }^{53}$ carried out surveys of perceived safety in 24 car parks in urban and suburban areas of Albany in the USA. Test participants were transported to the sites in four vehicles and they visited the sites in different orders. At each site, they were asked to walk around and then describe lighting using questionnaires which included ratings of perceived safety when walking alone. The results show 
that ratings of safety are place-specific: a particular illuminance does not lead to a particular level of safety because illuminance is only one of many environmental factors that contribute to evaluation of safety. Hence, instead of simply comparing illuminance against ratings of safety after dark, illuminance was plotted against the difference between daytime and nighttime ratings of safety, effectively using the daytime rating in each location as control for the nighttime rating. It was found that as illuminances increased, the difference between ratings of perceived safety recorded at daytime and nighttime tended to decrease (Figure 5). In other words, higher illuminances increased reassurance after dark towards the level experienced in daytime at that same location. These data suggest an optimum horizontal illuminance of 10 lux; higher illuminances do not tend to improve reassurance at a particular location relative to the level of reassurance in daytime at that same location. There is however a need to confirm whether these data are appropriate for residential roads where light levels are typically lower (2.0 lux to 15 lux $)^{1}$ than the car parks surveyed by Boyce et al. which had mean horizontal illuminances of up to 50 lux.

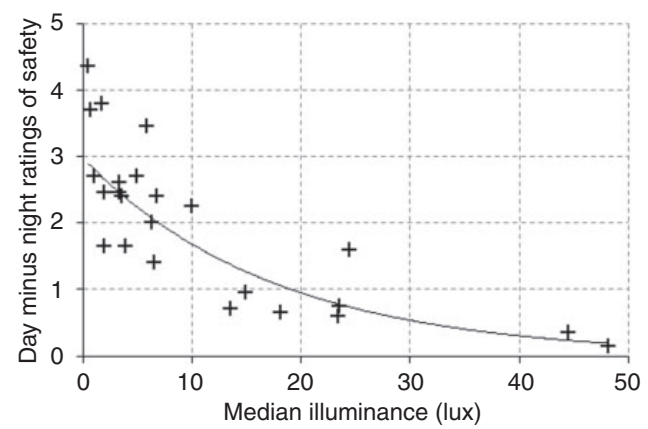

Figure 5 Difference between daytime and nighttime ratings of perceived safety of car parks plotted against median illuminance, after Boyce et al. ${ }^{53}$
In these studies, the test participants were able to observe the change in illuminance, and therefore, the potential to improve reassurance by means of higher illuminance must be considered with caution because it may be that the improvement to reassurance is obtained only when higher illuminance is noted by respondents. Atkins et al. ${ }^{51}$ report that $96 \%$ of respondents noted a change to the lighting. Vrij and Winkel ${ }^{35}$ employed an independent samples approach with $49 \%$ of the 160 passers-by rating the before condition and $51 \%$ the after condition: because the study was conducted on two successive Fridays, with the enhanced lighting being installed in-between, then it is likely that these passers-by would have noticed the increase in light level. In Boyce et al., ${ }^{53}$ the repeated measures design meant that test participants were exposed to changes in illuminance at night at the different sites.

The results of one study do not suggest that higher light levels improve reassurance. Dravitzki et al. ${ }^{16}$ surveying the same group of people (homeward bound commuters in Wellington, New Zealand, between the hours of 1715 and 1830) at three different times of year to gain responses under three different lighting conditions - daylight, twilight and after dark. Their survey sought perceptions of the adequacy of road lighting and the likelihood of experiencing antisocial behaviour. The results do not suggest a significant difference between survey periods and thus that light level did not affect the perceived likelihood of antisocial behaviour. Figure 5 demonstrates that this result is expected if the illuminance is sufficiently high, but this was not reported.

In summary, there is evidence that lighting of higher illuminance improves reassurance $35,43,50,51,53$ although further evidence is needed to confirm whether this effect may be limited to situations where the higher illuminance is noticeable. The study from Boyce et $a l .{ }^{53}$ provides evidence for an optimum 
illuminance and this requires validation in contexts relevant to the current focus of lighting in residential areas.

\subsection{Lamp spectrum}

There is evidence that a location considered to be brighter will also be considered safer. ${ }^{12}$ At mesopic levels of adaptation lighting from lamps of higher scotopic/photopic (S/P) ratio tends to appear brighter, for example scenes lit by lamps such as MH and fluorescent appear brighter than when lit by HPS lamps of equal illuminance, ${ }^{54,55}$ and thus lighting of higher $\mathrm{S} / \mathrm{P}$ ratio may also enhance reassurance. The $\mathrm{S} / \mathrm{P}$ ratio is an interesting metric for outdoor lighting, providing characterisation of visual performance ${ }^{56}$ in addition to spatial brightness $^{54}$ and is the basis of new road lighting guidance in the UK. ${ }^{57,58}$

There is evidence that higher $\mathrm{S} / \mathrm{P}$ ratio enhances reassurance in the results of three field studies ${ }^{34,59,60}$ where the existing HPS lighting was replaced by lamps of broader spectral distribution and the environment evaluated by pedestrians using rating scales before and after the change. Morante ${ }^{59}$ surveyed two roads; in one, HPS lighting providing an average illuminance of 8.7 lux was replaced by electrodeless fluorescent (QL) lighting providing $2.7 \mathrm{lux}$; in the second road, HPS lighting providing an average illuminance of 3.2 lux was replaced by $\mathrm{MH}$ lighting providing 3.1 lux. Akashi et al. ${ }^{60}$ compared HPS street lighting with that from a $6500 \mathrm{~K}$ fluorescent lamp, these providing average photopic illuminances of 3.4 lux for the HPS lamp and 2.8 lux for the fluorescent lamp. In these two studies, the lower photopic illuminances of the after lighting were chosen so that the before and after lighting provided equal unified luminance. ${ }^{61}$ In the final study, $\mathrm{Knight}^{34}$ reported evaluations of the perception of brightness and safety before and after road lighting was changed from HPS to one of two types of $\mathrm{MH}(2800 \mathrm{~K}$ and $4200 \mathrm{~K})$, with average illuminances in the given areas being similar before and after the change of lamp. In all three studies, the new lighting was found to provide higher ratings of safety than did the HPS, these differences being confirmed to be statistically significant in two studies. 34,60

In any before and after study, it is possible that respondents are responding to the attention being given to their local area, a Hawthorn-like response, rather than to a purposeful change in lighting characteristics, or alternatively their responses are inflated by the high initial lumens of new lamps. The existing installation may have been near the end of its useful working life, with the inherent lamp failures, depreciated lumen output and dirty luminaires, whilst the new installation was clean and benefited from the initial over-lighting included to offset subsequent lumen depreciation. However, if this initial response is the one that residents retain, that may be considered a useful contribution to resident satisfaction. An interesting feature of Knight's ${ }^{34}$ study is that a reverse change was included, in which the MH lighting was replaced with HPS lighting: The results suggest a statistically significant reduction in the perception of safety $(p<0.05)$. What this result suggests is that the change in SPD mattered: further confirmation would be useful.

\subsection{Spatial distribution of light}

Variations in the spacing and height of lamp posts and luminaire optics produce different patterns of light distribution. Guidance for road lighting design tends to use measures of spatial distribution associated with variations of illuminance across the lit surface (uniformity of horizontal illuminances). Kostic and Djokic ${ }^{62}$ compared subjective evaluations of $\mathrm{MH}$ and LED lighting along a footpath, with one of their rating scales seeking evaluation of perceived safety. Safety was rated better under the MH lighting than under the LED lighting $(p<0.01)$ as 
were most of the items evaluated. The two types of lamp were carefully chosen to enable direct comparison of $\mathrm{MH}$ and LED as sources: both had similar correlated colour temperature (CCT) $(3000 \mathrm{~K})$, similar high Colour Rendering Index (CRI: $R_{\mathrm{a}}>80$ ), the SPD curves are similar, used identical luminaires, and both met the requirements of lighting class P3 (although the illuminances actually achieved are not reported). One apparent difference between the types of lighting is the spatial distribution, as illustrated in luminous intensity diagrams. It is reported that the MH lighting had 'much better' illuminance uniformity, commonly meaning a higher ratio of the minimum to average illuminances, although this is not quantified. These results hint that higher uniformity leads to better reassurance, but this remains to be validated using a priori selection of uniformities.

The results from three studies ${ }^{63-65}$ indicate that alternative approaches to spatial distribution should be considered. Haans and de Kort $^{63}$ compared three variations of spatial distribution using a row of five luminaires (Figure 6): Conventional (all set to the same light output), ascending (low light level at observation point, increasing light level further away) and descending (high light level at observation point, decreasing light level further away), with all three designed to provide the same overall amount of light. In this experiment, variation in spatial distribution was achieved by changing the light output of different luminaires, but the light distribution of individual luminaires was unchanged. Evaluations were recorded using two procedures, a forced-choice pairwise comparison of preference, with all possible pairs presented in a counterbalanced order, and a separate evaluation of the individual installations using a 5-point response scale to report agreement with statements such as $I$ would rather avoid this street, again with presentation order counterbalanced. The results indicated a significant effect of spatial distribution on perceived safety with the ascending distribution rated significantly less safe than conventional and descending for perceived personal safety $(p<.0 .01)$ but only a marginal difference $(p=0.07)$ between the conventional and ascending distributions. This trend was found using both procedures.

The distributions used in the Haans and de Kort study may have exaggerated the effect of spatial distribution: In the ascending and descending arrangements, the end light fittings were set to $1 \%$ or $80 \%$ of maximum output. A further study of spatial distribution was carried out by Viliunas et al. ${ }^{64}$ who used a similar experimental design but with less extreme variation in illuminance. In this study, test participants stood under the first of three lamp posts in an outdoor location, these spaced at $30 \mathrm{~m}$ distances. The light output of each lamp was set to either $100 \%$, $50 \%$, or $10 \%$ of maximum and seven combinations of light pattern (including 10/50/ $100,10 / 100 / 100$ and $100 / 50 / 50)$ were observed in a random order. When set to $100 \%$ output, horizontal illuminance at the pavement was 23 lux and 13 lux under a post and in the middle of two posts, respectively. Evaluations were carried out using a series of semantic differential rating scales including dim/bright, calming/scary and dangerous/safe. It was found that evaluations were dependent primarily on the luminous flux of the light source in the first luminaire, with a higher illuminance enhancing reassurance, whereas for equal luminous fluxes of the light source in the first luminaire, the luminous fluxes of the light sources in the second and third luminaires were less important.

Further support for these results is found in the study by Vrij and Winkel ${ }^{35}$ who found that respondents walking towards the brighter lighting (illuminance increased by a factor of 5) were better reassured (reported less fear) than subjects walking away from the light - suggesting a desire to be in the brighter 


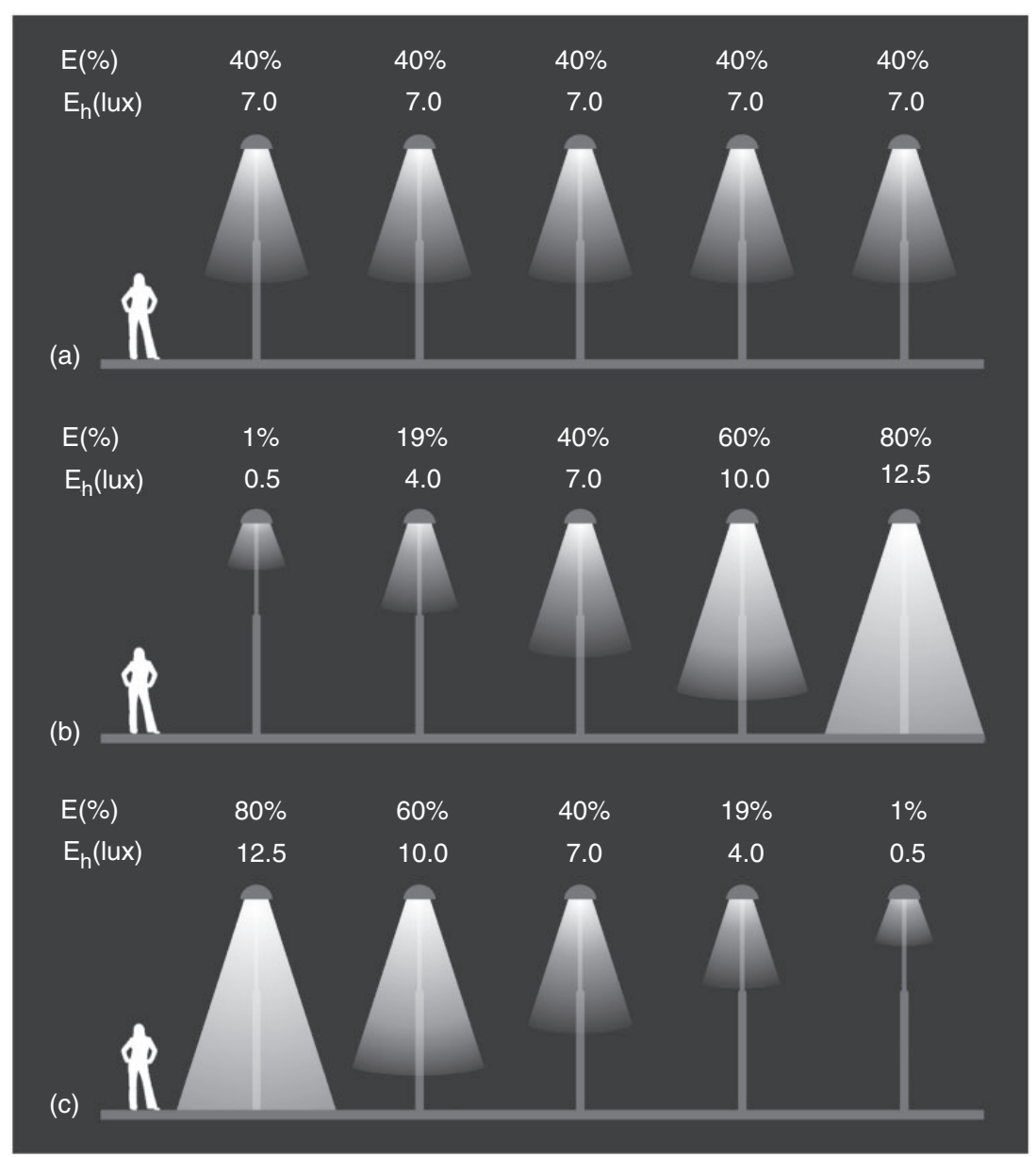

Figure 6 The spatial distributions of illuminance examined by Haans and de Kort. ${ }^{63}$ These are: conventional (a), ascending (b) and descending (c) light distributions. $E(\%)$ is the percentage of the maximum output of a luminaire. $E_{\mathrm{h}}$ (lux) is the horizontal illuminance at street level straight underneath the lamp post. Reprinted from Journal of Environmental Psychology, 32/4, Haans A and de Kort YAW, Light distribution in dynamic street lighting: Two experimental studies on its effects on perceived safety, prospect, concealment, and escape, 342-352, copyright (2012), with permission from Elsevier.

space rather than the dimmer space. The findings might also be influenced by the spacing between luminaires and the luminaire light distribution, e.g. if there were there dark patches between the luminaires.

A further study examined spatial distribution in relation to objects in the scene. ${ }^{66} \mathrm{KuO}$ et al. proposed that adding foliage increases public use of a previously barren space, thereby increasing levels of natural surveillance which might help people to feel safer and deter crime. Judgements of preference and safety using daytime photographs in which foliage had been digitally manipulated revealed that increasing tree density and grass maintenance had a positive effect on preference and reassurance. ${ }^{67}$ Subsequent analysis of police crime reports and level of foliage around 98 buildings over a two-year period revealed that higher levels of foliage led to fewer property crimes and violent crimes. ${ }^{68}$ These results give some context for the study 
by Nikunen and Korpela ${ }^{66}$ who found that directing the focus of light to the natural elements of a scene (e.g. trees and grassland) rather than the man-made elements (e.g. car parks) led to higher ratings of restoration or recovery of mental fatigue: Nikunen et al. ${ }^{65}$ demonstrated that lighting promoting restoration would also promote feelings of safety.

Spatial distribution is usually controlled by setting limits on illuminance uniformity, which for subsidiary roads in the UK is the ratio of the minimum illuminance to the average illuminance. ${ }^{49}$ Further research is needed to determine the relationship between uniformity and reassurance. The findings presented by Haans and de Kort ${ }^{63}$ and Viliunas et al. ${ }^{64}$ suggest a reassurance benefit is gained by creating a brighter environment in the immediate vicinity of a pedestrian. For a single pedestrian walking along an otherwise empty road, this suggests the need for dynamic variation of illuminance from static road lighting or for lighting that tracks the pedestrian's location. The results from Nikunen and Korpela $^{66}$ suggest the need to highlight discrete natural elements. Further research is needed to consider how such variation in spatial distribution could be included in design guidance. It may be considered impractical or unreasonable to expect the lighting designer to respond to these variations. Attempting to do so may lead to further problems. For example, the dynamic variation in illuminance suggested by results from Haans and de $\mathrm{Kort}^{63}$ may be a source of annoyance to residents if used along a residential road.

\section{Behaviour change}

One reason for investigating reassurance is that there is a link with walking: a low level of reassurance (or, a high level of fear) can lead to constrained behaviour such as deciding to use an alternative means of transport to walking or to avoid going out at all, and walking is of wider interest because it is a common means by which physical activity can be introduced into people's daily routines in order to encourage good health. ${ }^{69}$ In terms of behaviour constraints, it is the perception of safety that influences behaviour rather than physical safety ${ }^{12}$ and in most cases the risk of being a victim of criminal offences is of more importance to pedestrians than the risk of being involved in an accident. ${ }^{70}$ If good lighting can increase reassurance, this in turn may lead to an increase in walking.

There is evidence that improved lighting leads to behaviour change. Painter ${ }^{26,27}$ found an increase in pedestrian use (males 101\% and females $71 \%$ ) of a crime blackspot following relighting. Donker et al. ${ }^{71}$ found a significant effect of light on walking speed, with the average walking speed of pedestrians in their evening unlit condition being faster than in the evening lit or daylight conditions. Evidence as to whether lighting effects the decision to walk would be interesting. Improved outdoor lighting may also be advantageous in attracting people/tourists to an area, improving the nighttime economy. ${ }^{72}$

Psychological distress caused by fear of crime may lead to some people remaining prisoners in their homes, ${ }^{73}$ and this may affect the elderly and females in particular. ${ }^{33,74,75}$ These groups would particularly benefit from the better reassurance gained from improved lighting. Clearly, there are limitations to expected effects of lighting. Reluctance to walk into certain areas may be because of the danger of drink-related disorder or unruly and violent behaviour by groups of young males ${ }^{33}$ and better lighting is unlikely to address this.

The factors considered to be important may change with age. Bernhoft and Carstensen $^{32}$ sought reasons for route choice by pedestrians and cyclists: For the younger group (40-49 years old), the desire to arrive (most direct route and fastest route) was the most frequently reported; for the older group ( $>70$ years old), the presence of a footpath or cycle path was the most important. 


\section{Conclusion}

The first aim of this paper was to determine whether lighting enhances reassurance. Using quantitative methods such as category rating, results from several studies suggest that lighting is associated with reassurance. ${ }^{21,22,31}$ While consideration of methodology may place doubt in any one study, in particular that the procedure may have led respondents toward such conclusion, that they converge toward the same conclusion gives reason to place confidence in this conclusion. This paper presents the results of a new experiment that used an unfocussed, qualitative procedure, and this confirmed that lighting was associated with reassurance when the procedure did not prompt focus on lighting.

The second aim was to determine how the characteristics of road lighting might be used to enhance pedestrian's reassurance when walking after dark. Higher illuminance leads to higher reassurance. ${ }^{35,53}$ The study by Boyce et $a l .{ }^{53}$ of car parks in the USA demonstrates a method for using ratings of reassurance to identify an optimum illuminance. Their data suggest an optimum illuminance (10 lux) above which further increase has little effect on reassurance, but further research is needed to validate this in the context of residential roads, these tending to have a lower illuminance than US car parks, and also to determine if the effect is apparent when the variation in illuminance is not obvious. Lighting of higher $\mathrm{S} / \mathrm{P}$ ratio appears brighter at mesopic levels ${ }^{54}$ and there is evidence that lighting of $\mathrm{S} / \mathrm{P}$ ratio also enhances reassurance. ${ }^{3}$

The spatial distribution of light is conventionally described by the uniformity of horizontal illuminances. The results of one study $^{62}$ give evidence that higher uniformity enhances reassurance, but this is in need of validation using a range of uniformities. There is some evidence that distributing light to highlight natural objects rather than artificial objects enhances reassurance. ${ }^{65,66}$ Finally, two studies demonstrate that spatial distribution needs to consider the location of the pedestrian, ${ }^{63,64}$ for example, a possible preference for brighter lighting in the immediate vicinity of a pedestrian, and thus the need for dynamic control over spatial distribution. Spatial distribution is the least wellinvestigated characteristic: there is a need to repeat past studies to extend and confirm the findings, and to consider how the lighting designer might respond to these issues.

It should be noted however that in the decision as to what route to take the effect of lighting may be outweighed by the desire for a fast, direct route or the absence of trip hazards ${ }^{32}$ and also that the effect of lighting on reassurance needs also to consider physical features, in particular that a place with a high level of entrapment might not benefit significantly from a change of lighting. ${ }^{12}$ Furthermore, the type of walking might matter. Alfonzo ${ }^{76}$ defines three different types of walking (destination walking, strolling walking and combination walking) and the different motivations behind these may affect the significance of lighting, for example 'optional' strolling walking might be more easily affected than 'compulsory' destination walking.

\section{Funding}

This work was carried out through support from the Engineering and Physical Sciences Research Council (EPSRC, grant reference EP/H050817).

\section{References}

1 Commission Internationale de l'Éclairage. Lighting of Roads for Motor and Pedestrian. CIE publication 115. Vienna: CIE, 2010.

Lighting Res. Technol. 2015; 47: 449-469 
2 Farrall S, Jackson J, Gray E. Social Order and the Fear of Crime in Contemporary Times. Oxford: Oxford University Press, 2009.

3 Lorenc T, Petticrew M, Whitehead M, Neary D, Clayton S, Wright K, Thomson H, Cummins S, Sowden A, Renton A.

Environmental interventions to reduce fear of crime: Systematic review of effectiveness.

Systematic Reviews 2013; 2: 30-40.

4 Cambridge Dictionaries online. Retrieved 24 October 2013, from http://dictionary. cambridge.org/dictionary/british/reassurance.

5 Merriam-Webster. Retrieved 24 October 2013, from http://www.merriam-webster.com/ dictionary/reassurance.

6 Dictionary.com. Retrieved 24 October 2013, from www.dictionary.reference.com/browse/ reassurance.

7 Department of the Environment and Welsh Office. Planning Out Crime. Circular 5/94. London: HMSO, 1994.

8 Cozens PM, Neale RH, Whitaker J, Hillier D, Graham M. A critical review of street lighting, crime and fear of crime in the British city. Crime Prevention and Community Safety: An International Journal 2003; 5: 7-24.

9 Chang C-L. Spatial design and reassurance for unfamiliar users when wayfinding in buildings. PhD thesis. Sheffield: University of Sheffield, 2009.

10 Findlay C, Southwell K. 'You Just Follow the Signs': Understanding visitor wayfinding problems in the countryside: Proceedings of Open Space: People Space, An International Conference on Inclusive Environments, Edinburgh, Oct 27-29: 2004.

11 Fisher BS, Nasar JL. Fear of crime in relation to three exterior site features: Prospect, refuge, and escape. Environment and Behavior 1992; 24: $35-65$.

12 Blöbaum A, Hunecke M. Perceived danger in urban public space. The impacts of physical features and personal factors. Environment and Behaviour 2005; 37: 465-486.

13 Herzog TR, Flynn-Smith JA. Preference and perceived danger as a function of the perceived curvature, length and width of urban alleys. Environment and Behavior 2001; 33: 653-666.
14 Greene M, Greene R. Urban safety in residential areas: Global spatial impact and local selforganising processes: Proceedings of the 4th International Space Syntax Symposium, London: 2003: 52.1-52.8.

15 Luymes DT, Tamminga K. Integrating public safety and use into planning urban greenways. Landscape and Urban Planning 1995; 33: 391-400.

16 Dravitzki VK, Cleland BS, Walton D, Laing JN. Measuring commuting pedestrians' concerns for personal safety and the influence of lighting on these concerns: Proceedings of the 26th Australasian Transport Research Forum, Wellington, New Zealand, Oct 1-3: 2003.

17 Boyce PR, Gutkowski JM. The if, why and what of street lighting and crime: A review. Lighting Research and Technology 1995; 27: 103-112.

18 Acuña-Rivera M, Uzzell D, Brown J. Perceptions of disorder, risk and safety: The method and framing effects. Journal of Environmental Psychology 2011; 2: 167-177.

19 Poulton EC. Bias in Quantifying Judgements. Hove, UK: Lawrence Erlbaum Associates, 1989.

20 Tourangeau R, Rips LJ, Rasinski K. The Psychology of Survey Response. Cambridge: Cambridge University Press, 2000.

21 Loewen LJ, Steel GD, Suedfeld P. Perceived safety from crime in the urban environment. Journal of Environmental Psychology 1993; 13: 323-331.

22 Hanyu K. Visual properties and affective appraisals in residential areas after dark. Journal of Environmental Psychology 1997; 17: 301-315.

23 Toet A, van Schaik MG. Effects of signals of disorder on fear of crime in real and virtual environments. Journal of Environmental Psychology 2012; 32: 260-276.

24 Austin DM, Sanders C. Graffiti and perceptions of safety: A pilot study using photographs and survey data. Journal of Criminal Justice and Popular Culture 2007; 14: 292-316.

25 Bishop ID, Rohrmann B. Subjective responses to simulated and real environments: A comparison. Landscape and Urban Planning 2003; 65: 261-277. 
26 Painter K. The impact of street lighting on crime, fear and pedestrian street use. Security Journal 1994; 5: 116-124.

27 Painter K. The influence of street lighting improvements on crime, fear and pedestrian street use, after dark. Landscape and Urban Planning 1996; 35: 193-201.

28 Nair G, Ditton J, Phillips S. Environmental improvements and the fear of crime: The sad case of the 'pond' area in Glasgow. British Journal of Criminology 1993; 33: 555-561.

29 Okuda S, Ishii J, Fukagawa K. Research on the lighting environment in the street at night. Part 1. Resident's attitude on the safety and security in the street at night: 26th Session of the CIE, Beijing, Jul 4-11: 2007.

30 Koga Y, Tanaka R, Shibata D. Evaluation structure on night streets. A case study in Fukuoka: 25th Session of the CIE, San Diego, Jun 25-Jul 2: 2003: D5 82 - D5 85.

31 van Cauwenberg J, Clarys $\mathrm{P}$, de Bourdeaudhuij I, van Holle V, Verté D, de Witte N, de Donder L, Buffel T, Dury S, Deforche B. Physical environmental factors related to walking and cycling in older adults: The Belgian ageing studies. Public Health 2012; 12: 142 ..

32 Bernhoft IM, Carstensen G. Preferences and behaviour of pedestrians and cyclists by age and gender. Transportation Research Part F 2008; 11: 83-95.

33 Ramsay M, Newton R. The Effect of Better Street Lighting on Crime and Fear: A Review. Crime Prevention Unit paper No. 29. London: The Home Office, 1991.

34 Knight C. Field surveys investigating the effect of lamp spectrum on the perception of safety and comfort at night. Lighting Research and Technology 2010; 42: 313-330.

35 Vrij A, Winkel FW. Characteristics of the built environment and fear of crime: A research note on interventions in unsafe locations. Deviant Behavior: An Interdisciplinary Journal 1991; 12: 203-215.

36 Farrall S, Bannister J, Ditton J, Gilchrist E. Questioning the measurement of the fear of crime: Findings from a major methodological study. British Journal of Criminology 1997; 37: 657-678.
37 Lee M. The genesis of fear of crime. Theoretical Criminology 2001; 5: 467-485.

38 Farrall S, Gadd D. The frequency of the fear of crime. British Journal of Criminology 2004; 44: 127-132.

39 Gray E, Jackson J, Farrall S. Feelings and functions in the fear of crime: Applying a new approach to victimisation insecurity. British Journal of Criminology 2011; 51: 75-94.

40 Bishop G, Tuchfarber A, Oldendick R. Opinions on fictitious issues: The pressure to answer survey questions. Public Opinion Quarterly 1986; 50: 240-250.

41 Tversky A, Kahneman D. Judgment under uncertainty: Heuristics and biases. Science, New Series 1974; 185(4157): 1124-1131.

42 Loo D. The 'Moral Panic' that Wasn't. In: Lee M, Farrall S. (eds) Fear of Crime: Critical Voices in an Age of Anxiety. London:

Routledge, 2009: pp. 12-31.

43 Matsui T. A study on a street lighting that makes change illuminance is effective for both reducing fear of crime and saving energy: 26th Session of the CIE, Beijing, Jul 4-11: 2007: D5-112 - D5-115.

44 Sutton RM, Farrall S. Gender, socially desirable responding and the fear of crime. British Journal of Criminology 2005; 45: 212-224.

45 Lane J, Meeker JW. Women's and men's fear of gang crimes: Sexual and nonsexual assault as perceptually contemporaneous offenses. Justice Quarterly 2003; 20: 337-371.

46 Unwin J, Fotios S. Does lighting contribute to the reassurance of pedestrians at night-time in residential roads? Ingineria Iluminatului 2011; 13: 29-44.

47 Martin DW. Doing Psychology Experiments. 4th Edition, Pacific Grove, CA: Brooks/Cole Publishing, 1996.

48 Burnard P. Searching for meaning: A method of analysing interview transcripts with a personal computer. Nurse Education Today 1994; 14: 111-117.

49 British Standards Institution. Code of Practice for the Design of Road Lighting Part 1: Lighting of Roads and Public Amenity Areas. BS 5489-1:2013. London: BSI, 2012.

50 Ishii J, Okuda S, Fukagawa K. Research on the lighting environment in the street at night. Part 
2. The effect of the lighting environment in the street on the insecurity feeling: 26th Session of the CIE, Beijing, Jul 4-11, 2007.

51 Atkins S, Husain S, Storey A. The Influence of Street Lighting on Crime and Fear of Crime. Crime Prevention Unit, Paper No. 28. London: Home Office, 1991.

52 Nair G, McNair DG, Ditton J. Street lighting: Unexpected benefits to young pedestrians from improvement. Lighting Research and Technology 1997; 29: 143-149.

53 Boyce PR, Eklund NH, Hamilton BJ, Bruno LD. Perceptions of safety at night in different lighting conditions. Lighting Research and Technology 2000; 32: 79-91.

54 Fotios SA, Cheal C. Predicting lamp spectrum effects at mesopic levels. Part 1: Spatial brightness. Lighting Research and Technology 2011; 43: 143-157.

55 Fotios SA, Cheal C. Lighting for subsidiary streets: Investigation of lamps of different SPD. Part 2: Brightness. Lighting Research and Technology 2007; 39: 233-252.

56 Commission International de l'Éclairage. Recommended System for Visual Performance Based Mesopic Photometry. CIE Publication 191 b. Vienna: CIE, 2010.

57 Fotios S, Goodman T. Proposed UK guidance for lighting in residential roads. Lighting Research and Technology 2012; 44: 69-83.

58 Institution of Lighting Professionals. Lighting for Subsidiary Roads: Using White Light Sources to Balance Energy Efficiency and Visual Amenity. Professional Lighting Guide PLG03:2012. Rugby, UK: ILP.

59 Morante P. Mesopic Street Lighting Demonstration and Evaluation: Final Report for Groton Utilities, Groton, CT. Troy, NY: Lighting Research Center, 2008.

60 Akashi Y, Rea M, Morante P. Progress Report: Improving Acceptance and Use of Energy-Efficient Lighting. Unified Photometry: An Energy-Efficient Street Lighting Demonstration in Easthampton, MA. Troy, NY: Lighting Research Center, 2004.

61 Rea MS, Bullough JD. Making the move to a unified system of photometry. Lighting Research and Technology 2007; 39: 393-408.

62 Kostic A, Djokic L. Subjective impressions under LED and metal halide lighting. Lighting
Research and Technology. First published online on 13 June 2013, doi:10.1177/ 1477153513481037.

63 Haans A, de Kort YAW. Light distribution in dynamic street lighting: Two experimental studies on its effect on perceived safety, prospect, concealment, and escape. Journal of Environmental Psychology 2012; 32: 342-352.

64 Viliûnas, H. Vaitkevičius, R. Stanikunas, P. Vitta, R. Bliumas, A. Auškalnytè, A. Tuzikas, A. Petrulis, L. Dabašinskas, Žukauskas A. Subjective evaluation of luminance distribution for intelligent outdoor lighting. Lighting Research and Technology. First published online on 21 June 2013, doi:10.1177/ 1477153513491760.

65 Nikunen H, Puolakka M, Rantakallio A, Korpela K, Halonen L. Perceived restorativeness and walkway lighting in near-home environments. Lighting Research and Technology. First published online on 20 February 2013, doi:10.1177/ 1477153512468745.

66 Nikunen H, Korpela KM. The effects of scene contents and focus of light on perceived restorativeness, fear and preference in nightscapes. Journal of Environmental Planning and Management 2012; 55: 453-468.

67 Kuo FE, Bacaicoa M, Sullivan WC. Transforming inner-city landscapes: Trees, sense of safety, and preference. Environment and Behavior 1998; 30: 28-59.

68 Kuo FE, Sullivan WC. Environment and crime in the inner city: Does vegetation reduce crime?. Environment and Behavior 2001; 33: 343-367.

69 Loukaitou-Sideris A. Is it safe to walk? 1. Neighborhood safety and security considerations and their effects on walking. Journal of Planning Literature 2006; 20: 219-232.

70 Fyhri A, Hof T, Simonova Z, de Jong M. The influence of perceived safety and security on walking: Proceedings of Walk21; Getting Communities Back on their Feet, Den Haag, Netherlands, Nov 16-19: 2010: 49-70.

71 Donker SF, Kruisheer J, Kooi F. Pedestrian walking speed as a tool to study environment behaviour: Proceedings of the 9th Biennial Conference on Environmental Psychology, 
Eindhoven University of Technology, Sept 26-28: 2011.

72 Entwistle J. Trail blazing. Lighting Journal 2013; 78: 14-17.

73 Schweitzer JH, Kim JW, Mackin JR. The impact of the built environment on crime and fear of crime in urban neighborhoods. Journal of Urban Technology 1999; 6: 59-73.

74 Beaulieu M, Dubé M, Bergeron C, Coisineau M-M. Are elderly men worried about crime? Journal of Aging Studies 2007; 21: 336-346.

75 Roman CG, Chalfin A. Fear of walking outdoors: A multilevel ecologic analysis of crime and disorder. American Journal of Preventative Medicine 2008; 34: 306-312.

76 Alfonzo MA. To walk or not to walk? The hierarchy of walking needs. Environment and Behavior 2005; 37: 808-836. 